\title{
Conceptualizing community buy-in and its application to urban farming
}

\author{
Melissa N. Poulsen, ${ }^{*}$ Marie L. Spiker, ${ }^{\mathrm{b}}$ and Peter J. Winch ${ }^{\mathrm{a}}$ \\ Johns Hopkins Bloomberg School of Public Health
}

\begin{abstract}
Submitted August 11, 2014 / Revised October 8, 2014 / Accepted November 21, 2014 / Published online December 16, 2014

Citation: Poulsen, M. N., Spker, M. L., \& Winch, P. J. (2014). Conceptualizing community buy-in and its application to urban farming. Journal of Agriculture, Food Systems, and Community Development, 5(1), 161-178. http://dx.doi.org/10.5304/jafscd.2014.051.014
\end{abstract}

Copyright (C) 2014 by New Leaf Associates, Inc.

\begin{abstract}
Supporters of urban farming - a type of urban agriculture that emphasizes income generation view it as a productive use of vacant land, increasing access to fresh produce and contributing to local economies. Yet its viability depends on gaining "community buy-in" (i.e., the acceptance and active support of local residents). While recognized as important to the success of socially oriented programs, information is lacking regarding effective processes for gaining community buy-in. Through participant observation at urban farms
\end{abstract}

\footnotetext{
a Social and Behavioral Interventions Program, Department of International Health, Johns Hopkins Bloomberg School of Public Health, Baltimore, Maryland, USA

b Human Nutrition Program, Department of International Health, Johns Hopkins Bloomberg School of Public Health, Baltimore, Maryland, USA

* Corresponding author: Melissa N. Poulsen, 615 North Wolfe Street, Baltimore, Maryland 21205 USA; mpoulsen@jhu.edu
}

\section{Author note}

The research funding for this study was provided through a doctoral fellowship from the Johns Hopkins Environment, Energy, Sustainability, and Health Institute. and interviews with urban farmers, neighborhood leaders, city residents, and key stakeholders in Baltimore, Maryland, we explored the perceived importance of community buy-in for urban farming, as well as the barriers, facilitators, and strategies for gaining such buy-in. Findings reveal consensus regarding the importance of buy-in, justified by farms' vulnerability to vandalism and the need to align farm services with local residents' desires. Barriers to buy-in include unfamiliarity of residents with urban farming, concerns about negative impacts on the neighborhood, and perceptions of urban farms as "outsider projects." Buy-in is facilitated by perceived benefits such as access to fresh produce, improvement of degraded lots, employment and educational opportunities, the creation of community centers, and community revitalization. Strategies urban farmers use to gain community support followed three main phases: (1) gaining entry into a neighborhood; (2) introducing the idea for an urban farm; and (3) engaging the neighborhood in the urban farm. We make recommendations based on these three phases to assist urban farmers in gaining community buy-in and discuss themes that can be applied to community buy-in processes more broadly. 


\section{Keywords}

community acceptance, community buy-in, community participation, local food systems, qualitative methods, urban agriculture, urban farming

\section{Introduction}

Urban farming is a type of urban agriculture that emphasizes income-generating agricultural activity. Urban farms are generally categorized as either community farms (which are driven by social goals) or commercial farms (which are production-focused), and so can be run as nonprofits or for-profits. However, unlike the more familiar community gardens, in which the growers consume their own produce, urban farms grow food for commercial distribution, selling produce through venues such as neighborhood farm stands, farmers markets, and restaurants.

Urban planners, public health practitioners, and local food advocates have promoted urban farming in many U.S. cities, including Baltimore, Maryland, the site of this study. In Baltimore, this enthusiasm stems from concerns about an overabundance of vacant properties, a lack of access to healthy foods in many low-income neighborhoods, and high unemployment rates, three interrelated problems that urban farms are seen as addressing. Over a dozen urban farms have started in Baltimore since 2010, and while most reflect the efforts of individuals and community groups, the municipal government also supports urban farming, including through an innovative initiative that leases vacant city-owned land to experienced farmers (Baltimore Office of Sustainability, n.d.).

While excitement for urban farming abounds among experts, it is important also to consider the perspectives of city residents whose neighborhoods host urban farms, particularly given critiques of urban agriculture as a white-dominated practice that occurs primarily in black and Latino neighborhoods, with little participation from within those communities (Hoover, 2013). Questioning the inclusivity of urban agriculture, Hoover (2013) recently called for an expanded research agenda that includes the perspectives of more ethnically and racially diverse populations on urban agriculture. Heeding this call and operating under the assumption that urban farming is most viable if it has the support of local communities, the aim of our study was to determine effective processes for gaining the "buy-in" of city residents for urban farming. Drawing upon findings from interviews with urban farmers, neighborhood leaders, residents, and key stakeholders, participant observation of urban farms, and incorporating feedback from a stakeholder dissemination meeting, we explored the perceived importance of community buy-in for urban farming, as well as the barriers, facilitators, and strategies for gaining such buy-in. Based on these findings, we propose a series of recommendations to assist urban farmers in gaining community buy-in for future farming projects that are embraced by local residents.

\section{Conceptualizing Community Buy-in}

Though the term "buy-in" originates in the financial sector, it has been adopted by implementers of projects ranging from the promotion of physical activity (Kahn et al., 2002) to tourism development (van der Stoep, 2000) to describe stakeholders', participants', and local community members' acceptance of and willingness to actively support projects. Despite recognition of the importance of community buy-in to a project's success and survival, there appears to be a major gap in the literature regarding effective processes for gaining community buy-in.

Two related concepts have been researched more widely: community participation and community acceptance. Community participation refers to "the social process of taking part (voluntarily) in either formal or informal activities, programs and/ or discussions to bring about a planned change or improvement in community life, services, and/or resources" (Bracht \& Tsouros, 1990, p. 201). This broad definition is appropriate given the many ways that community participation is conceptualized. While a variety of classifications of community participation have been proposed, Morgan (2001) captures the main conceptual dichotomy. The utilitarian perspective sees participation as a collaborative effort in which community members agree to collaborate with an externally determined project, often contributing resources in return for some expected benefit. The empowerment perspec- 
tive sees participation as local community members taking responsibility for identifying and working to solve their own problems.

The risk in labeling what we refer to as "community buy-in" as community participation is that despite categorizations of community participation that include weaker participatory forms, the term often connotes the empowerment perspective. From this perspective, community ownership is seen as a critical outcome of participation, with community members defining their own health or social agenda and committing to long-term community involvement in the project (Bracht \& Tsouros, 1990). In contrast, projects seeking community buy-in may desire community input and involvement in project activities, but ownership and control of these (often preconceived) projects ultimately lie with the outside organization.

Community acceptance has not been as widely researched, but research on social acceptance of the placement of renewable energy production sites (e.g., wind farms) may be applicable to our research on urban farming since both relate to community reactions to a physical change in landscape. In a special issue of Energy Policy on this topic, community acceptance is defined as acceptance "by local stakeholders, particularly residents and local authorities" (Wüstenhagen, Wolsink, \& Bürer, 2007, p. 2685) for decisions and projects. Unlike the empowerment model of community participation, community acceptance is sought for predetermined projects; community involvement is generally limited to the planning phase; and ownership of the project clearly lies with the sponsor. Though there is significant overlap between community acceptance and community buy-in, these concepts are not synonymous in that "acceptance" implies a more passive compliance whereas "buy-in" insinuates active support.

Thus community buy-in is not equivalent to community participation or acceptance, but instead provides a unique end goal that has utility for the introduction of new projects. That said, there are limitations to using the term "buy-in" that should be addressed up front. First, considering its origin in the corporate world, buy-in can carry a financial connotation that may be inappropriate for socially oriented programs. In the case of urban farming, this connotation is not entirely irrelevant, considering that urban farming emphasizes incomegenerating agricultural activity and commercial urban farms are run as small businesses. Second, community buy-in may be construed as jargon that is not accessible to a lay audience. For these reasons, organizations might choose to use terms such as "community support" when describing their programmatic goals, particularly when communicating with participants. In this paper, we use the term "community buy-in" despite these limitations because (a) we believe it aptly describes the space that lies on the continuum between community participation and acceptance; and (b) the term is frequently used, but poorly described, in the context of health and social justice programming. As such, processes for achieving buy-in within the context of health and social justice programming need to be defined. Through this case study of urban farming in Baltimore, we seek to contribute to the task of determining effective processes for gaining community buy-in.

\section{Methods}

We used a qualitative, collective case study methodology to explore the relationship between urban farms located in residential neighborhoods and the residents living in proximity to them. This methodology involves studying an issue through multiple bounded systems (in our case, urban farms) using several sources of information (Creswell, 2007). We deemed this methodology appropriate considering its usefulness in gaining an in-depth understanding of each case, and we employed a collective case study approach in order to explore the farmcommunity relationship among urban farms in different stages of development. Cases comprised three types: (1) "active farms" included neighborhoods where there was an urban farm that had been operational for more than one year ( 2 sites); (2) "new farms" included neighborhoods where there was a vacant lot where a new urban farm was planned to be established (2 sites); and (3) "rejected farms" included neighborhoods where a proposal to start an urban farm on a vacant lot was withdrawn based on objections from residents (1 site). 
Selection of Urban Farming Sites for Case Studies

The farms selected for inclusion were located in residential areas in Baltimore, Maryland, and within direct view of multiple households, thus increasing the relevance and salience of the topic for interviewees. The cases included both community farms and commercial farms. Among the two new farm sites, one had just broken ground at the time data collection began and was in production by the time data collection was complete, while no farmingrelated activity occurred at the second site during the study period.

The neighborhoods surrounding each farm site were mostly low-income, with a greater proportion of residents living below the poverty line (between $21 \%$ and $37 \%$ ) as compared to Baltimore as a whole $(18 \%)$. The exception was the rejected farm site, which bordered two neighborhoods, one of which had a lower rate of poverty $(12 \%)$ than Baltimore as a whole. The majority of residents living in our study sites were black (ranging from $79 \%$ to $97 \%$ of the neighborhood's population, compared to $64 \%$ of all Baltimore residents) (Baltimore Neighborhood Indicators Alliance, n.d.). ${ }^{1}$

\section{Data Collection Procedures}

Data were collected from October 2012 to October 2013 by the first two study authors and a trained research assistant. In order to understand the ways in which urban farming projects attempt to gain community support and how residents respond to these efforts, we conducted in-depth interviews with 49 individuals, including key stakeholders with expertise related to urban farming $(n=8)$, urban farmers associated with each site $(n=8)$, and neighborhood leaders $(n=12)$ and adult residents from the study neighborhoods $(n=21)$. Farmers, neighborhood leaders (which included members of neighborhood associations), and key stakeholders were purposively selected for participation. Residents were selected through snowball sampling. All interviewees except key stakeholders received US $\$ 20$ as an incentive to participate. Interviews were semistructured following prompts from an open-ended discussion guide that was

${ }^{1}$ Income data is from 2011; race and ethnicity data is from 2010. refined over the course of the study to follow up on emergent themes. Interviews lasted approximately one hour and took place at a location of the participants' choosing, frequently a public space such as a library or the relevant urban farm.

In order to gain a contextual understanding of our research sites and the issues discussed during interviews, we also conducted 16 unstructured participant observations (totaling 25 hours) throughout the study period at farm sites in which there was ongoing activity, including volunteering during farm volunteer hours, shopping at neighborhood farm stands, and attending community events held at the farms. Observations focused on who was present during farm activities (including passersby), interactions between individuals, and the attitudes expressed about the urban farm and its relationship to the neighborhood. We wrote detailed notes immediately following each observation. At one new farm site and the rejected site where no activity occurred, we viewed the vacant lot where the proposed farms were to be located.

\section{Data Analysis}

Interviews were audio-recorded and transcribed verbatim, and transcripts were pooled by interviewee type (key stakeholders, urban farmers, neighborhood leaders, and residents) for data analysis. Data analysis followed a thematic approach, performed primarily by two of the researchers. We first developed a codebook by identifying themes relevant to our study aim from a subset of interviews. After coding each group of transcripts, we wrote comprehensive summaries for each code illustrated by direct quotations - a process of interpretive review that formed the findings from each interviewee type. We then integrated the summary for each code across interviewee types, looking for points of convergence and divergence. Following this process, we read the participant observation notes, looking for observations relevant to the thematic codes and adding this data to the summaries. Based on these findings, we developed draft recommendations for gaining community buy-in for urban farms. We then held a dissemination meeting during which study participants and other stakeholders provided feedback on the draft recommendations through discussion and 
written feedback. This feedback was incorporated into our final set of recommendations.

\section{Data Quality}

The credibility of our research was enhanced in several ways. First, the in-depth study of multiple cases led to a richer conceptual interpretation of farm-community relationships. Triangulation of the data through the use of multiple methods of data collection (interviews and participant observation) and interviewee types also improved the study's ability to credibly capture a comprehensive understanding of the community buy-in process. Additionally, conducting numerous interviews among different interviewee types over the course of a year strengthened our confidence in having obtained adequate data saturation. Finally, the dissemination meeting provided an opportunity for member validation of our findings and to refine our recommendations to best reflect the lived experience of our research participants.

\section{Ethical Considerations}

The Johns Hopkins Bloomberg School of Public Health Institutional Review Board approved this study. Interview participants provided verbal informed consent prior to participating in the study.

\section{Results}

We first discuss our findings related to the importance of community buy-in for urban farming projects. We then describe the barriers and facilitators to achieving buy-in, as well as the strategies farmers and others ${ }^{2}$ use to gain community buy-in for urban farming. The final section of our results describes the outcome of our stakeholder dissemination meeting and provides our final set of recommendations.

\section{Importance of Community Buy-in for Urban Farms} We found consensus regarding the importance of

\footnotetext{
2 We use "urban farmer" to refer to the individuals, organizations, or companies that start and manage an urban farm. For simplicity, we discuss strategies that urban farmers use to gain community buy-in, but in some instances, municipal government offices are also actively involved in this process.
}

community buy-in for urban farms located in residential areas. While neighborhood leaders were most ardent in their views, with several emphasizing the importance of community buy-in to the viability of any new project or business that enters a neighborhood, other interviewees saw a specific need for urban farms to become "a part of the neighborhood" since farms are not traditionally located in cities.

Opinions varied as to the degree of community buy-in that is necessary. For example, one farmer stated that a few outspoken naysayers should not "keep you from serving all these other people that live in the neighborhood." In contrast, one key stakeholder noted the difficulty that arises when even a "small minority of people" is opposed to an urban farm:

It's very hard to say to your neighbor, "I don't care how upset you are. This is going in front of our houses..." Nobody wants to ruin other people's experiences of their safe space, their home space.... It can't really be like a purely democratic process. Like 51\% is not enough. (Key stakeholder)

The most common justification for community buy-in provided across interviewees was to build understanding and solidarity so community members will help protect the farm. In the spirit of creating a welcoming atmosphere (and in some cases, to save money), many urban farms are not fenced, so there is little to deter people from entering. Therefore, as one stakeholder stated, if people are opposed to a farm, they "can come in the middle of the night and slash all the plastic up on your hoop house....and stomp on your plants." Many neighborhood leader and resident interviewees confirmed this concern about vandalism, with one resident stating, "If you don't have the neighborhood backing you, then you're pretty much gone.... It's not going to last long. It'll be done in six months."

According to interviewees, engaging neighborhood residents alleviates this concern by creating respect for and a sense of ownership of the farm, which can result in residents keeping an eye out for it. Every urban farmer we interviewed described 
community support as the best form of security for an urban farm, an opinion backed by the fact that our study sites had experienced minimal vandalism.

The second reason given for needing community buy-in relates to the potential of urban farms to serve the surrounding neighborhood. According to some interviewees, urban farmers must engage residents to ensure their projects provide benefits that resonate with local residents, rather than making assumptions about what the neighborhood desires. One stakeholder emphasized the need for a purposeful process to gaining community buy-in if an urban farming project aims to "help" the neighborhood.

[Otherwise] you're there for this self- righteous idea you have for yourself, but you're not trying to allow the community to grow with your idea... you'll always have that tension there.... I can have the greatest idea, but if people... don't feel the benefits of it because they haven't bought into the idea, then it's really just a great idea that won't go nowhere. (Key stakeholder)

\section{Barriers and Facilitators to Community Buy-in} We identified several common barriers that can negatively affect city residents' views of urban farming, as well as a wide range of perceived benefits associated with urban farming that positively influence residents' reactions. These are summarized with exemplary quotations in Tables 1 and 2.

\section{Table 1. Barriers to Gaining Community Buy-in for Urban Farming Identified in Qualitative Interviews in Baltimore City}

\begin{tabular}{|c|c|}
\hline Barrier & Exemplary Quotation \\
\hline $\begin{array}{l}\text { Lack of familiarity } \\
\text { with urban farming }\end{array}$ & $\begin{array}{l}\text { People don't have a mental image. They hear "farm" and maybe they picture cows or fields of } \\
\text { wheat, or tractors, and they just don't see how that could possibly fit into an urban environment. } \\
\text { (Key stakeholder) }\end{array}$ \\
\hline $\begin{array}{l}\text { Concern about the } \\
\text { appearance of urban } \\
\text { farms }\end{array}$ & $\begin{array}{l}\text { You're not up a dirt road where just your two immediate neighbors are seeing you. You really have } \\
\text { a responsibility...to keep it looking sharp, to keep it beautiful.... Where you could have some } \\
\text { equipment lying around, or where you could leave a pile of woodchips sitting at the corner of your } \\
\text { plot for a while in the country, you just can't do that in the city. (Key stakeholder) }\end{array}$ \\
\hline $\begin{array}{l}\text { ear that an urban } \\
\text { arm will attract rats } \\
\text { the neighborhood }\end{array}$ & $\begin{array}{l}\text { I was thinking about thousands...of rodents just running - all migrating to this one area, you } \\
\text { know, and it'll be really a mess. (Resident, new farm) }\end{array}$ \\
\hline $\begin{array}{l}\text { Worry that urban } \\
\text { farms will fall victim } \\
\text { to vandalism }\end{array}$ & $\begin{array}{l}\text { So far, nobody's done anything to [the farm]....And l'm really kind of surprised.... [Interviewer: } \\
\text {...Why's that?] Because it's Baltimore City! You got dysfunctional children, you have drug } \\
\text { addicts...and all kinds of people who just constantly coming through this neighborhood. (Resident, } \\
\text { new farm) }\end{array}$ \\
\hline $\begin{array}{l}\text { Concern about the } \\
\text { safety or cleanliness } \\
\text { of food grown on } \\
\text { urban farms }\end{array}$ & $\begin{array}{l}\text { There was a lot of concern in the neighborhood. A farm there? [Residents] really didn't think it } \\
\text { was a good idea....'Cause that area was so filthy. There was so much trash. So much rats. A lot of } \\
\text { folks threw out mattresses. It was like a dumping ground. It was really bad, I mean not some place } \\
\text { you wanna eat from. (Neighborhood leader, active farm) }\end{array}$ \\
\hline $\begin{array}{l}\text { Concern that urban } \\
\text { farms may replace } \\
\text { other potential } \\
\text { development }\end{array}$ & $\begin{array}{l}\text { It's city-owned land that we're talking about, so really, it belongs to the community.... We're } \\
\text { choosing land that is not being used for any positive purposes...But still, there is the potential that } \\
\text { it could be used for anything. And so to give it - even for a period of just five years - to private } \\
\text { individuals for a for-profit purpose, that maybe feels like something is being taken away from you, } \\
\text { even if it's just the potential opportunity of something else that could serve people more broadly. } \\
\text { (Key stakeholder) }\end{array}$ \\
\hline $\begin{array}{l}\text { Distrust of urban } \\
\text { farming projects that } \\
\text { are run by "outsiders" }\end{array}$ & $\begin{array}{l}\text { So I think that initially starts with a disbelief in thinking that somebody is coming in - again, white } \\
\text { spoiled kids - are coming in to take advantage of their neighborhood. Even though obviously } \\
\text { nobody was claiming that land before. (Resident, active farm) }\end{array}$ \\
\hline $\begin{array}{l}\text { Concern about the } \\
\text { sustainability of } \\
\text { urban farms }\end{array}$ & $\begin{array}{l}\text { You know that we're coming in from the outside, and we have the idea about what's best for your } \\
\text { neighborhood, and it's not something that you came up with...lt's us just coming in and plopping it } \\
\text { down. And then maybe we just walk away, and let it fall to pieces and become an } \\
\text { eyesore....People have experience of that. Sometimes experience that's decades old, but that's } \\
\text { still very resonant. (Key stakeholder) }\end{array}$ \\
\hline
\end{tabular}


Table 2. Services Urban Farms Are Perceived to Provide Neighborhoods in Baltimore City

\begin{tabular}{|c|c|}
\hline Service & Exemplary Quotation \\
\hline $\begin{array}{l}\text { Increased access to fresh } \\
\text { produce }\end{array}$ & $\begin{array}{l}\text { It's going to bring more people around because like I said, some people like fresh } \\
\text { vegetables... people... will come around and want some vegetables, so it's going to be } \\
\text { nice for the neighborhood. (Resident, new farm) }\end{array}$ \\
\hline $\begin{array}{l}\text { Use of degraded vacant lots } \\
\text { for productive uses }\end{array}$ & $\begin{array}{l}\text { I think it was very exuberant feeling and exciting to see something like [the farm] } \\
\text { happening in the area, because before it was just an empty plot of land and when that } \\
\text { happens and there's always an accumulation of garbage, bottles, and things of that sort. } \\
\text { So just to see a group of people really energized to change it and to also not only do it for } \\
\text { themselves, but to give back to the community. (Resident, active farm) }\end{array}$ \\
\hline $\begin{array}{l}\text { Employment opportunities for } \\
\text { local residents }\end{array}$ & $\begin{array}{l}\text { We need to create jobs. And this is why l'm more interested in for-profit farming because I } \\
\text { think that the value that urban farms can bring to the city is not just the food that it } \\
\text { harvests, but I think that there are a thousand jobs that we could create if we were } \\
\text { serious about local food production. From composting to growing food, processing food, } \\
\text { washing it, packaging it, distributing it, selling it. (Urban farmer, rejected farm) }\end{array}$ \\
\hline $\begin{array}{l}\text { Educational opportunities } \\
\text { about the provenance of food, } \\
\text { agricultural processes, and } \\
\text { nutrition, particularly for youth }\end{array}$ & $\begin{array}{l}\text { People don't understand where your food comes from, how to grow it, why it costs so } \\
\text { much. So that's the nice point about urban farming, it shows people what it takes, you } \\
\text { know to actually put something on the plate. (Urban farmer, new farm) }\end{array}$ \\
\hline $\begin{array}{l}\text { Provision of a central space } \\
\text { that brings the community } \\
\text { together }\end{array}$ & $\begin{array}{l}\text { It may sound cliché, but it helps the community grow itself because you have more people } \\
\text { that are involved and taking care and you have a sense of, you know, this is mine, this is } \\
\text { where I live. You have a sense of pride. (Resident, active farm) }\end{array}$ \\
\hline $\begin{array}{l}\text { Revitalization of the broader } \\
\text { community }\end{array}$ & $\begin{array}{l}\text { I think that these urban farms have the potential for urban revitalization. I think they have } \\
\text { the potential to take an area that is in a downward spiral, begin positive momentum. } \\
\text { (Urban farmer, new farm) }\end{array}$ \\
\hline
\end{tabular}

Strategies Used to Gain Community Buy-in

Figure 1 outlines the strategies for gaining community buy-in that emerged from our findings. These strategies fell into three main phases: (1) gaining entry into a neighborhood; (2) introducing the idea for an urban farm to a neighborhood; and (3) engaging the neighborhood in the urban farm.
Phase 1. Gaining entry into a community

The first phase refers to the early strategies urban farmers use to develop ties within a neighborhood. While these were generally discussed as useful for farmers who are not from the neighborhood in which they plan to farm, we found that even those who farmed in their own neighborhood drew upon these strategies to help garner broader support.

Figure 1. Strategies Used by Urban Farmers in Baltimore City to Gain Community Buy-in

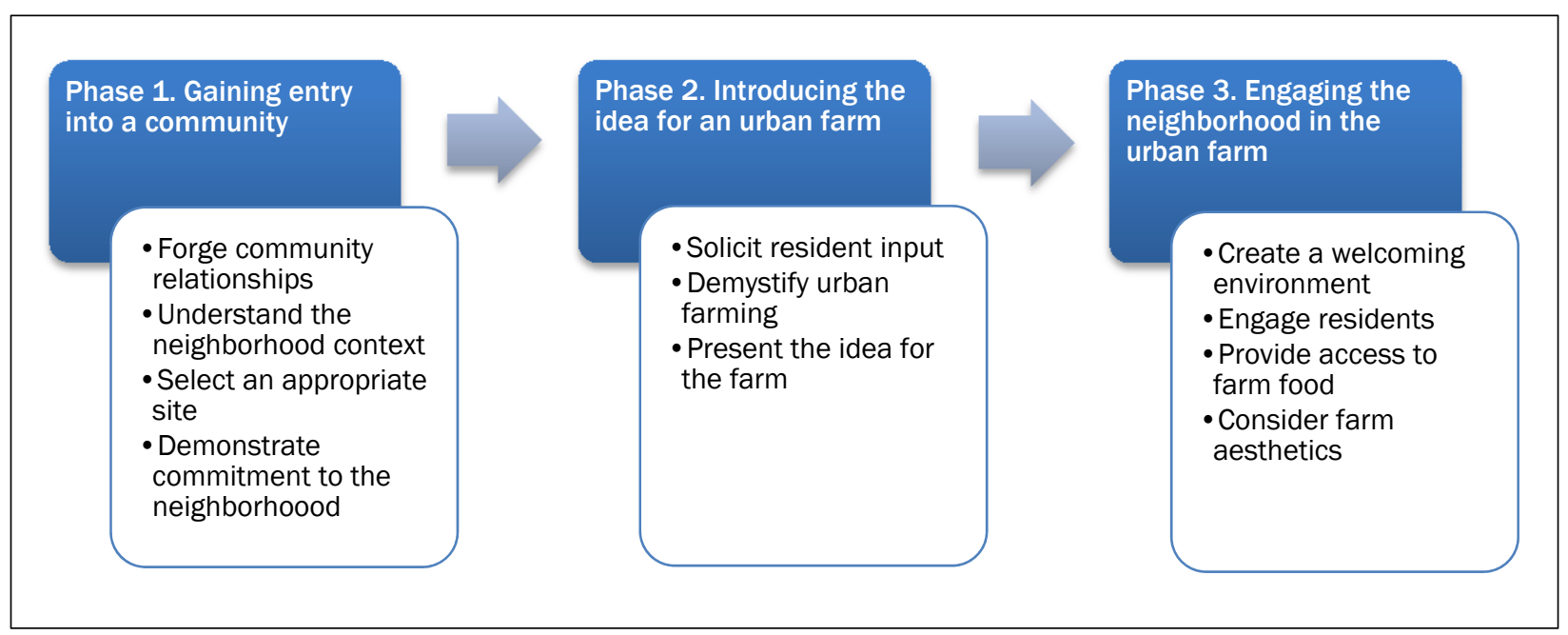


Forging community relationships. Interviewees recommended building relationships with individuals and community groups as a way of gaining entry in a neighborhood and as a precursor to all other steps in the process. Interviewees discussed two key strategies to build community relationships: (1) identifying community leaders who can act as champions for the farm, such as civically engaged residents, community association representatives, leaders of community-based organizations, and city council members; and (2) collaborating with community groups with an established presence in the neighborhood.

Most urban farmers we interviewed relied on community associations to facilitate entry into a neighborhood, as these associations can play critical roles in garnering broader community buy-in. These groups were in full support of all the active and new farms in our study before the farmers ever broke ground. A drawback to relying on community associations is that because they are viewed as official entities that can grant "permission" for the development of urban farms, they can obscure the voices of residents outside of the community associations. Several interviewees raised concerns about the lack of representativeness of community associations, particularly at the rejected farm site, where a potentially supportive neighborhood was unable to override opposition to the proposal for a new urban farm from a community association that was viewed as unrepresentative of the neighborhood.

In addition to community associations, some urban farmers we interviewed had established formal partnerships with community-based organizations in the neighborhood. This had facilitated the process of gaining the trust of local residents for the urban farm, alleviating skepticism about the farm being managed by individuals from outside the neighborhood.

Understanding the neighborhood context. To gain entry into a neighborhood, it is important for urban farmers to understand the current and historical context of the neighborhood. One interviewee framed this approach as:

...recognizing that you're part of an evolving organism of your neighborhood that has been around for a long time. And figuring out how to work with people who are there, and have been there, and have been working on these issues for a long time. And not being really presumptive about what your role might be before building those connections. (Key stakeholder)

Gaining this understanding allows urban farmers to ensure a farm is a reasonable fit for the neighborhood, build on existing resources, and identify ways the urban farm can provide services to the neighborhood that are valued by residents, rather than — as one stakeholder put it — assuming "you know more about what this community needs than what the community knows." One neighborhood leader complimented an urban farmer for such efforts:

It was clear that they did their research about [the neighborhood]. They looked at something that would be appealing to us and they tailored their message TO us...I feel like it would have shut people off before they even were presented all the great things that, was like, "Y'all don't know this area." But it was clear that they did their research. (Neighborhood leader, rejected farm)

Selecting an appropriate site. A farmer looking for land to start an urban farm must not only consider parameters such as its slope, exposure to sunlight, and soil quality, but also the role it plays in the neighborhood's social environment. For example, trash-filled vacant lots act to degrade neighborhoods, so their transformation to a productive farm is often a welcome change. In contrast, urban farmers in our study avoided vacant lots that were actively used by residents, even when used for informal purposes such as parking for cars. As one farmer explained, "You have to look at the utility of the land...the way that residents look at it."

\section{Demonstrating commitment to the neighbor-}

hood. A final strategy in this phase relates to the perception that urban farmers are "outsiders" potentially exploiting the neighborhood's resources. 
Based on our findings, this view is more common when farmers are not residents of the neighborhood in which they farm or are of a different race from the majority of residents, and stems from a history of strained racial relations in Baltimore. We found that urban farmers overcome this perception by demonstrating their dedication to the larger neighborhood. Toward this end, some interviewees felt it is important for farmers to move to the neighborhood in which they are farming.

I do think the ownership has to be local.... Because if not it's just like somebody's just found a good place to plop their factory, and then they go home at night. But you learn so much by being IN the community. (Resident, rejected farm)

Other farmers found acceptance by taking an active role in the community, for example, by attending community association meetings, or by having a visible presence at the farm and engaging passersby.

In honesty... first I thought the majority of the people that were up there were white people. And I thought it was gonna benefit them. And then, [the farmers] came out in the community strong. And my whole thought just turned around.... They got involved with the community association, they would bring stuff to the meetings, they knocked on every door darn near around here. And they gave samples out....It wasn't, "Cause we white, we gonna do this and... take it over here..." They gave back right to the community. (Resident, active farm)

\section{Phase 2. Introducing the idea for an urban farm to a neighborhood}

The second phase addresses the way in which a farm is introduced to the neighborhood.

Resident input. One of the strongest themes that emerged on gaining community buy-in was the need to allow residents to have a voice in the planning process. Neighborhood leaders warned that not soliciting local input would breed resis- tance to the farm, regardless of the merits of the project, framing such inclusiveness as a matter of fairness.

That directly affects our home, not theirs, so for anybody to have more say in it than us, that would not be fair... We're the ones that's going to feel the impact of everything the most. (Neighborhood leader, new farm)

Underscoring these sentiments is the idea that residents should be involved early on, before any farming activity starts. Otherwise, interviewees warned that efforts to involve the community may be seen as self-serving, for example to meet the requirements of a grant. One neighborhood leader applauded the urban farmers in his neighborhood for their early and open approach:

This is someone who says, "We have an idea. We wanna know what the community thinks about it!... We wanna ENGAGE with you." And that's so different than a lot of people who come into the neighborhood. They have their plans all made up, and they come to the association, and say, "We've got this plans, we've got this money, this is what we're gonna do, we want a letter of support." (Neighborhood leader, active farm)

Demystifying urban farming. Considering that a common barrier to community buy-in for urban farming is city residents' lack of familiarity with the activity, an important component of this phase is to "demystify" urban farming. Many resident interviewees had no exposure to an urban farm until one appeared in their own neighborhood. Most of these interviewees expressed initial skepticism, but across the board, their doubts were alleviated once they saw the farm up and running. To avoid the initial skepticism and give residents an idea of what to expect from an urban farm, interviewees suggested sharing examples of existing farms, for example by using diagrams of potential farm layouts and "before and after" photos of existing urban farms, as well as inviting neighborhood leaders to visit an existing urban farm. 
Presenting the idea for an urban farm. Our findings revealed two common approaches to introducing the farm proposal to a neighborhood: presenting at community meetings and going doorto-door to speak with residents living around the potential farm site. Neighborhood leaders expressed appreciation for the high level of detail that urban farmers provided in their presentations, which included potential benefits of the farm, mock-ups of the space, and an explanation of the farm's management.

Because of that, the simplicity of their presentation, it didn't seem like they were putting on smoke and mirrors. You know, very straightforward, this is it, we're laying it out all before you, there's no behind-thescenes things that we're trying to keep from your eyes. (Neighborhood leader, rejected farm)

Interviewees also thought it critical to emphasize how an urban farm can benefit a neighborhood and attributed the positive reception some farmers have received to their effective articulation of how a farm would alleviate problems in the neighborhood, such as improving access to fresh vegetables or mitigating illegal dumping on a vacant lot.

Interviewees noted the importance of communicating with residents about their concerns regarding urban farming. Several interviewees specifically recommended proactively addressing widespread concern about farms attracting rats to a neighborhood. This concern was reported to be the main cause of resistance for developing an urban farm at the rejected farm site and escalated so quickly that the farmers never had an opportunity to address the issue.

\section{Phase 3. Engaging the neighborbood in the urban farm} The third phase involves an ongoing process to encourage local residents to engage with the farm. Such efforts appear to positively affect community buy-in by further demystifying urban farming and facilitating respect for the farm.

Creating a welcoming environment. One prerequisite to neighborhood engagement is creating a welcoming and inclusive environment at urban farms, which includes the physical space as well as the manner in which urban farmers interact with the neighborhood. One farmer discussed the importance of having a regular presence in the neighborhood, stating, "I think engaging with people and showing them around makes them feel like they are able to come in and get used to the project." We observed many instances of positive informal engagement with residents. For example, while volunteering at one active farm site, a woman walking by with her children stopped to question the farmer about a plant with which she was unfamiliar. In response, the farmer let each child try harvesting some of the Swiss chard and gave the woman a bunch to try, explaining how to cook it.

Interviewees also shared that a diversity of people involved with a farm creates a more inclusive environment:

For a lot of people, and certainly I'd say older African American residents, if you haven't been invited onto someone's space and you see them working, that's not your space to enter...So the more people we can get physically on the site itself, shows it's an open space....And if you don't see...somebody that looks like yourself, you might be less likely to join them. (Neighborhood leader, active farm)

Resident engagement. We found that urban farmers use a variety of strategies to engage residents on the farm, depending on their business model and the preferences of neighborhood residents. Some activities engage the broader neighborhood, such as hosting celebratory events at the farm, offering gardening workshops, creating neighborhood recipe books, and making farm produce available to residents. Other efforts engage a smaller number of residents in ongoing activities, creating strong allies for the farm. For example, at one active farm site, the urban farmers created a community garden on the lot across from the farm, giving residents ownership of part of the farm space. Of note, while volunteerism can create important relationships between volunteers and urban farms, it may not be an option for all city 
residents. Some resident interviewees were skeptical that local residents would have the time or desire to volunteer and even worried that an urban farm would not be viable if it relied upon residents' active involvement.

Youth participation was viewed as beneficial to community buy-in, as it provides a gateway for demystifying the farm for their families while also creating constructive activities for youth that are sorely lacking. Youth had become involved at the active farm sites through collaboration between the farms and local elementary schools, family-focused community events, and farm internships. Involvement was often informal; for example, at one active farm we observed that local youth were almost always present when the farmers were working, with one six-year-old girl calling the farm her "backyard."

Access to farm food. A key strategy for connecting local residents to an urban farm is providing access to the farm's produce. Nearly all the neighborhood leaders and residents we interviewed assumed that at least some portion of the food grown at their local urban farm would be made available to residents. This assumption was even made at sites where there were no opportunities for residents to purchase food.

Stakeholders generally suggested being generous with farm produce, giving away samples or selling produce in the immediate neighborhood at a lower price than would be sold at a farmers market in a more affluent neighborhood. However, some interviewees thought giving farm produce away for free would devalue it. As one stakeholder explained, residents are "more likely to eat it if they pay for it...I think that if they just put the food out in a bag and said 'it's for free,' it would just sit there." That said, many neighborhood leaders and resident interviewees assumed that food from an urban farm would be more affordable than supermarket produce since it "cuts out the middle man." Beyond cost, stakeholders discussed the importance of letting local residents have a say in what is grown and explained that many urban farms grow produce that local residents want to eat, even when that means growing certain crops that have a low return on investment.
Heirloom tomatoes are great, but we gotta get ones that look like the tomatoes in the stores a little bit. We need some orange carrots, we need beets that look standard. (Urban farmer, new farm)

Communication about the farm. The urban community farms we studied communicated with residents in order to keep them apprised of the farm's activities, promote events held at the farm, solicit volunteers, and market the farm's produce. Interviewees reported that the most effective communication strategies were face-to-face strategies such as signage on the farm, flyers given to passersby, knocking on doors of nearby residents, and providing samples of foods grown on the farm. Some farmers emphasized the importance of simply walking around the neighborhood and having spontaneous social interactions with residents. Others attended community association meetings on an ongoing basis as a part of their communication strategy. The two active farm sites also have an online presence, but urban farmers reported using online methods primarily to communicate with an audience beyond the neighborhood, since many residents do not use these forms of communication.

Farm aesthetics. While urban farms often inherently improve the appearance of a neighborhood by cleaning up the trash that has accumulated in a vacant lot, simply removing trash does not appear to be sufficient for gaining community buy-in. Urban farms face higher aesthetic standards than do rural farms. An added challenge noted by stakeholders is that a farm's first season is a critical time to cultivate community buy-in, but a farm is likely to look messy when farmers are setting up the farm. At one site where the farmers were significantly constrained in the amount of time they could devote to the farm, tension had arisen in the neighborhood regarding the farm's appearance. As a result, we observed many instances in which the farmers integrated considerations of appearance into their decisions about how they used their own and volunteers' time and the crops they planted, hoping to regain the community's goodwill. 


\section{Table 3. Summary of Recommendations for Gaining Community Buy-in for Urban Farming}

\section{Phase 1. Gaining entry into a neighborhood}

A. In choosing a farm site, ensure that local residents do not use the space for other purposes (e.g., family gatherings, parking, playfields) and that it provides an opportunity to improve blighted land.

B. Take steps to gain an understanding of the neighborhood context through such approaches as reaching out to neighborhood leaders, going door-to-door to speak with residents, and attending community meetings.

C. Avoid assumptions about what local residents desire and take steps to identify ways the urban farm can provide services that they value by speaking with a variety of community leaders and residents.

D. Forge relationships with community leaders or groups that can champion the idea for the farm and assist urban farmers in understanding the neighborhood context and how to incorporate goals into their project that are meaningful for residents.

E. Avoid perceptions that an urban farm is an "outsider project" by demonstrating dedication to the neighborhood through active community involvement, such as by attending community association meetings, hosting community events, partnering with local institutions, or informally engaging with residents.

Phase 2. Introducing the idea for an urban farm

F. Include local residents in the planning process for a new urban farm through such forums as community meetings or individual conversations with residents living in proximity to the potential farm site.

G. Demystify urban farming by sharing examples of other urban farms via photographs and tours.

$\mathrm{H}$. Proactively address common concerns about urban farming, including rats, vandalism, soil contamination, and food safety and sanitation, and explain potential benefits for the local neighborhood.

I. Use multiple forums to present the idea for the urban farm, including community meetings and engaging residents who live in direct proximity to the potential farm site.

\section{Phase 3. Engaging the neighborhood in the urban farm}

J. Create a welcoming environment at the urban farm site by engaging passersby, holding events at the farm, creating spaces where local residents can enjoy the green space, and considering ways to involve a diversity of people.

K. Create a variety of opportunities for residents to be involved, such as an associated community garden, community events, and opportunities for youth.

L. Provide opportunities for local residents to access farm produce. Consult residents to determine the types of food they prefer and convenient times and locations for distribution, and to ensure food is affordable.

M. Communicate with residents to encourage their engagement with the farm by distributing flyers, going door-to-door to speak with residents in close proximity to the farm, making announcements at community meetings, or using signage at the farm site.

N. Maintain and beautify the urban farm to meet residents' expectations for their neighborhood's appearance, including creating a sense of permanence in the space in the off-season (e.g., building structures like sheds and pergolas, planting trees).

Recommendations and Feedback from

Dissemination Meeting

Drawing upon these findings, we designed draft recommendations to assist urban farmers in their community buy-in efforts. The Appendix lists these draft recommendations and displays the ratings and comments received through the feedback process. There was little variation in ratings, with most recommendations viewed as moderately feasible for farmers to put into practice and quite beneficial to residents.

We drew upon this feedback to develop a final set of recommendations, which are presented in Table 3. While our findings suggest that commu- nity buy-in is essential for all urban farms located in residential areas, the degree to which urban farmers engage local communities will differ based on the goals they have for their farm. Therefore, these recommendations are not intended to be a checklist that is applied to every urban farming project, but rather a full spectrum of strategies for urban farmers to draw from when designing a process for community buy-in. Additional details on each recommendation are provided elsewhere (see Poulsen \& Spiker, 2014).

\section{Discussion}

In his call for urban agriculture research that is 
attentive to race and power dynamics, Hoover asks, "Is [urban agriculture] just another form of urban renewal, displacing underprivileged communities in the process, or is it an inclusive practice that works with marginalized people in the remediation of 'their' land?" (Hoover, 2013, p. 112). Our study demonstrates a trend toward the latter. Urban farmers, and particularly urban community farmers, in Baltimore view community support for their projects as crucial and employ numerous strategies to ensure that surrounding communities buy in to the farm.

Using a collective case study methodology facilitated a more comprehensive understanding of the farm-community relationship and the strategies that were successful in building positive relationships. In addition, the inclusion of the "rejected farm" case revealed what can go wrong during the community buy-in process. In this particular case, the urban farmers did not build relationships with influential community leaders, thus undermining their entry into the community; a few vocal community members' concerns about an urban farm attracting rats to their neighborhood fueled antagonism to the idea; and a community association that is viewed as unrepresentative of the neighborhood was given warrant to disapprove of the idea for an urban farm.

Based on our findings, we have proposed a set of recommendations to facilitate the process of gaining community buy-in for urban farming projects to ensure these projects are accepted and embraced by communities. While the specific recommendations pertain to urban farming, there are several themes that can be gleaned from these recommendations that are applicable to broader community buy-in processes. We discuss these themes below, also highlighting their relevance to similar processes of community participation and community acceptance.

\section{Fairness in the distribution of benefits and} drawbacks. Several of our recommendations point to a need for fairness in the distribution of benefits and drawbacks resulting from the development of an urban farm. New projects are unlikely to achieve community buy-in if they are perceived to deal advantages to some community members and disadvantages to others, defined as "outcome favorability" by Gross (2007). For example, when selecting a site for an urban farm (Table 3, recommendation A), if a vacant lot is chosen that is used by some residents - perhaps as a place for family cookouts - they may feel unfairly disadvantaged, negatively affecting their acceptance of the farm.

Fairness is a critical element of community acceptance, as demonstrated by research by Gross (2007) on the siting of a wind farm. She found that outcome favorability influences individuals who have a personal loss or gain at stake, while "outcome fairness" - an assessment of whether the outcome is fair for the community at large influences those without strong opinions on an issue. Based on our research, we conclude outcome fairness can influence community buy-in if the project implementer is perceived to be the only beneficiary. This highlights the importance of addressing concerns about urban farms and communicating the benefits an urban farm will bring to a neighborhood (recommendation $\mathrm{H}$ ). It also relates to recommendations to provide opportunities for local residents to access farm produce (recommendation L) and to meet residents' expectations for the farm's appearance (recommendation $\mathrm{N}$ ) so as to avoid perceptions that the farmer is benefitting from the project at the expense of the neighborhood.

Understanding the community context. The need to gain familiarity with the community context of a neighborhood was a common theme throughout our interviews (Table 3, recommendations $\mathrm{B}$ and $\mathrm{C}$ ). There were many justifications for this need: to address existing challenges or meet residents' desires through the farm's services, to build on existing resources in the neighborhood, and to demonstrate the farmers' interest in creating something of value for the neighborhood. To gain understanding of the local context, the urban farmers in our study forged relationships with community leaders or groups (recommendation D), along with attending community meetings on an ongoing basis and speaking informally with local residents.

Familiarity with the local community is also considered a necessity in community participation. 
In their seminal work on effective community participation, Bracht and Tsouros (1990, p. 203) suggest that one factor for successful community participation is "early and extensive knowledge of community history, organizational resources, influence structures and inter-organizational networks" and cite the value of community participation as a way of incorporating local values into programs.

Establishing trust in "outsiders." A recurring theme throughout our interviews was the view of urban farmers as "outsiders" who enter a neighborhood to change things, a perception that potentially breeds resistance to an urban farm. This was thought to stem in part from the fact that many urban farmers in Baltimore are white, farming in majority black neighborhoods. In their study of urban agriculture in Philadelphia, Meenar and Hoover (2012) similarly found that due to systemic and historical racism, non-whites are often suspicious of privileged whites coming in to start gardens. They also noted that Philadelphia is defined by class-conscious boundaries, where "any outsider coming into the neighborhood may be perceived as "other" (Meenar \& Hoover, 2012, p. 152). This may also be at play in Baltimore, where residents are similarly conscious of neighborhood boundaries.

Urban farmers were able to overcome this perception and gain the community's trust by demonstrating their dedication to the neighborhood, developing relationships with residents, and creating a welcoming environment (Table 3, recommendations $\mathrm{E}$ and $\mathrm{J}$ ). In their study of urban farming in Baltimore, Hu and colleagues (2011) similarly noted residents' distrust of "outsiders," concluding that to achieve buy-in farms should advertise their community-focused mission and demonstrate longevity.

This phenomenon has also been discussed in the community acceptance literature. In their introduction to the concept, Wüstenhagen and colleagues highlight the distrust that can arise when projects are instigated by community outsiders, warning, "trust in their aims, attitude and competence becomes an issue" (2007, p. 2687). And similar to our own findings, in research regarding community acceptance of planned pig production sites, Mann and Kögl (2003) found that the social integration of the farmer is a key factor for public acceptance, particularly if he or she comes from outside the community.

Local involvement in decision-making. One of the strongest themes to emerge from our interviews was the importance of involving residents in decision-making (Table 3, recommendation F). One aspect of such involvement is responding to concerns that arise (recommendation $\mathrm{H}$ ). Some urban farmers in our study went to great lengths to create opportunities for residents to be involved in decision-making by holding community meetings and consulting residents living in proximity to a potential farm site before ever breaking ground.

Involving communities in decision-making and planning is one of the main approaches to community participation, and the willingness by those in power to involve the community in decisionmaking is essential to its success (Bracht \& Tsouros, 1990; Buchan, 2003). However, scholars also caution against "tokenism" in community participation processes whereby communities are given opportunities to express their opinions, perhaps making the project look more credible in the process, while the "expert" ultimately makes the decisions about project design and management (Buchan, 2003; Butterfoss, 2006). While we found similar concerns, the urban farmers in our study who were committed to community involvement reported creating specific and transparent opportunities for residents to influence decision-making. In this way, flexibility and open-mindedness on the part of the project implementer can build trust in projects, particularly those started by community outsiders (Wüstenhagen et al., 2007).

Transparency. Transparency emerged as a key component in the community buy-in process for urban farming, exemplified by the fact that the entire second phase of this process relates to open communication. Two dimensions of transparency are relevant: (1) knowing what is meant by "urban farming" (demystifying urban farming, Table 3, recommendation $\mathrm{G}$ ); and (2) knowing what is being proposed for a specific site (recommendations I and $\mathrm{M}$ ). 
The importance of transparency throughout the process of planning a project is discussed in both the community participation literature and the community acceptance literature. For example, in her study of a wind farm siting, Gross (2007) found that perceived secrecy in the planning of the project was one of the main reasons community members viewed the process as unfair. This points to the importance of transparency in both the consultation process and the plans for a project. Through our research, we found an emphasis on the latter, but not on open communication about the consultation process itself; this may be something that should be considered in community buyin processes.

Community engagement. A final theme that emerged from our recommendations involves active engagement of the community in the urban farm's activities, as exemplified by the third phase of the community buy-in strategies (Table 3, recommendations J, K, L, M, and N). The buy-in efforts that are needed evolve over time, transitioning from activities that introduce the idea for the farm to ongoing activities that build and maintain relationships between community members and the urban farming project. Our findings suggest that this relationship is facilitated through community engagement. For example, numerous interviewees formed a positive impression of their neighborhood's urban farm after early involvement in the project, such as attending a farm event or volunteering.

Community engagement is a mainstay of community participation. However, the goal of such engagement is to achieve local action to solve specific problems (Bracht \& Tsouros, 1990) as opposed to involvement in project activities for the sake of building a relationship between the project and the community. In the literature on community acceptance, we have not seen discussion of community engagement with a project after the project is established. Thus community engagement in terms of ongoing interaction between local residents and a new project may be a unique aspect of community buy-in.

In discussing these themes, it is clear that there is significant overlap between processes of community buy-in, community participation, and community acceptance. Is there, then, utility in conceptualizing community buy-in as distinct? We believe there is, and that the difference lies not in the processes that are used, but in the end goals. From an empowerment perspective, the end goal of community participation is that local communities take responsibility for identifying and solving their own problems, while the end goal of community acceptance is agreement, or compliance, with a decision. We see community buy-in as a middle ground in the continuum lying between these two concepts, with the end goal being acceptance and active support by a community for a project or plan. Such support can encompass a broad range of actions, with the minimal level of buy-in equating to community acceptance, all the way to stronger participatory forms such as involvement and collaboration by communities. In addition, we identify community engagement, in terms of ongoing interaction and relationship-building between local residents and a new project, as a potentially unique aspect of community buy-in.

\section{Study Strengths and Limitations}

Through this research, we aimed to understand the relationship between geographic communities and urban farms and ultimately to determine effective processes for community buy-in. However, a limitation of this endeavor lies in the very use of the term "community," which is notoriously problematic in its implication of cohesiveness. Head (2007, p. 441) best sums this up, stating that the term "glosses over the social, economic and cultural differentiation of localities" implying "a (false and misleading) sense of identity, harmony, cooperation and inclusiveness." The views of our interviewees represent their specific social, economic, and cultural perspectives, inherently excluding others. Given the diversity of views present in any group, gaining the support of all members of a neighborhood for an urban farming project is an ideal rather than a reality.

One group whose input we were not able to incorporate is residents who are antagonistic toward the establishment of urban farms. Future research that elucidates the reasons for opposition 
to urban farming would strengthen our understanding of the community buy-in process. However, we were only able to identify one individual who was reportedly opposed to urban farming, and this individual was not interested in participating in this research; this may reflect a general lack of opposition to urban farming. The residents we interviewed frequently had an interest in urban agriculture or had established a relationship with the urban farm in their neighborhood and so were interested in the research topic, leading to rich and insightful interviews.

As with all qualitative research, it is important to consider contextual factors when transferring the findings of this study to settings beyond Baltimore. Baltimore is characterized by an overabundance of vacant land and widespread inaccessibility to fresh produce in poor neighborhoods, both of which drive grassroots enthusiasm and political will to support urban farming. However, based on the strength of our study methodology — including the inclusion of multiple cases, the triangulation of data and sources, and the integration of feedback received during the dissemination meeting - we are confident that the proposed recommendations provide a springboard for developing community buy-in processes that are tailored to meet the needs of a variety of urban farming models.

Future research on this topic should consider drawing from the experience of other types of small businesses in gaining community buy-in. Literature on the success of small businesses recognizes community buy-in as a criterion for success (Kilkenny, Nalbarte, \& Besser, 1999), and businesses themselves appreciate the importance of contributing to the public good above and beyond the goods and services they sell (Besser, 1999).
Though community urban farms more aptly parallel community-based nonprofit organizations, commercial farms may have more in common with other small businesses.

\section{Conclusion}

As urban farming continues to expand across the U.S., it is increasingly important to help farmers engage local communities so as to develop projects that thrive in the complex social landscape that defines urban farming. This includes supporting urban farmers as they work to balance the need to build strong relationships within the neighborhoods that host their projects while meeting the demands of production-level farming. Toward this end, the recommendations we propose provide a variety of strategies urban farmers can draw from when designing a process for community buy-in. In addition, we contribute a starting point for defining effective processes for gaining community buy-in within the context of health and social justice programming more broadly.

\section{Acknowledgements}

We would like to thank Nestor Mojica for his invaluable contributions to this study as a research assistant. We are also indebted to the many study participants who made this research possible by generously sharing their time and thoughts with us. We would also like to thank Dr. Larissa Jennings for reviewing drafts of this manuscript, and acknowledge the valuable feedback provided by the anonymous reviewers. This research was made possible by the Johns Hopkins Center for a Livable Future-Lerner Fellowship and a fellowship from the Johns Hopkins Environment, Energy, Sustainability, and Health Institute. 


\section{Appendix}

\section{Results from Feedback on Draft Recommendations from the Dissemination Meeting}

Feasibility and benefit ratings based on a scale from 1 to 5 , with 5 being the highest or best

\begin{tabular}{|c|c|c|c|}
\hline Draft recommendation & $\begin{array}{l}\text { Feasibility } \\
\text { for farmers }\end{array}$ & $\begin{array}{l}\text { Benefit to } \\
\text { residents }\end{array}$ & Selected qualitative feedback \\
\hline $\begin{array}{l}\text { Identify ways the farm can } \\
\text { support the neighborhood's } \\
\text { own goals }\end{array}$ & 3.19 & 4 & $\begin{array}{l}\text { - Recognize diversity within geographic communities and that } \\
\text { cohesive "neighborhood goals" do not exist } \\
\text { - Farmers should also build on resources and social capital } \\
\text { already in place } \\
\text { - Acknowledge the challenge farmers face in balancing } \\
\text { demands of production farming with community engagement }\end{array}$ \\
\hline $\begin{array}{l}\text { Build relationships with } \\
\text { community leaders or groups } \\
\text { who can be a champion for } \\
\text { the farm }\end{array}$ & 3.44 & 3.94 & $\begin{array}{l}\text { - Depth and quality of community relationships outweigh the } \\
\text { services provided by urban farms in terms of community } \\
\text { buy-in } \\
\text { - Important to build multiple relationships within } \\
\text { neighborhoods, not just with leaders of a single group }\end{array}$ \\
\hline
\end{tabular}

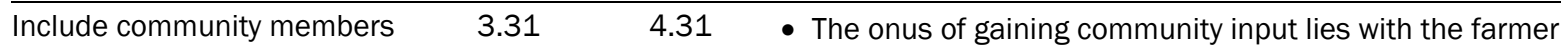
in the process of planning rather than placing demands on time and energy of residents the farm and leaders

- Farmers should approach the local community with a "blank slate," rather than a predetermined idea for an urban farm

- Recognize informal forms of community input (e.g., casual conversation)

- Important to acknowledge the agricultural knowledge that exists among neighborhood residents

\begin{tabular}{|c|c|c|c|}
\hline $\begin{array}{l}\text { Talk to local residents to } \\
\text { ensure an appropriate site is } \\
\text { selected for the urban farm }\end{array}$ & 3.63 & 4.38 & $\begin{array}{l}\text { - Enlist trusted organizations and/or individuals to facilitate this } \\
\text { process }\end{array}$ \\
\hline $\begin{array}{l}\text { Demystify urban farming for } \\
\text { residents in terms of what an } \\
\text { urban farm is like, including } \\
\text { addressing common concerns } \\
\text { and explaining potential } \\
\text { benefits }\end{array}$ & 3.31 & 4.31 & $\begin{array}{l}\text { - Understanding the neighborhood context can help frame the } \\
\text { idea for an urban farm for a particular neighborhood } \\
\text { - Sharing examples of other urban farms through tours or } \\
\text { before and after photos can be an effective method } \\
\text { - Ongoing and transparent communication about the purpose of } \\
\text { the farm is critical }\end{array}$ \\
\hline $\begin{array}{l}\text { Show dedication to the } \\
\text { neighborhood through active } \\
\text { involvement in the community }\end{array}$ & 3.25 & 4.44 & $\begin{array}{l}\text { - Finding opportunities for involvement is simple, but limited by } \\
\text { farmers' time and energy }\end{array}$ \\
\hline $\begin{array}{l}\text { Create opportunities for } \\
\text { residents to be involved with } \\
\text { the urban farm }\end{array}$ & 3.38 & 4.53 & $\begin{array}{l}\text { - Let residents define the ways they want to be involved } \\
\text { - Volunteerism is a limited mechanism for involvement } \\
\text { considering the demands it places on farmers and the lack of } \\
\text { feasibility for many residents }\end{array}$ \\
\hline $\begin{array}{l}\text { Provide opportunities for local } \\
\text { residents to access farm } \\
\text { produce }\end{array}$ & 3.38 & 4.75 & $\begin{array}{l}\text { - Challenges in making produce accessible include timing and } \\
\text { location of purchasing opportunities, effective advertising, and } \\
\text { ensuring food is desirable to residents } \\
\text { - Difficult to balance a farm's economic sustainability with } \\
\text { affordability of food }\end{array}$ \\
\hline $\begin{array}{l}\text { Ensure the urban farm meets } \\
\text { expectations for the neigh- } \\
\text { borhood's appearance }\end{array}$ & 3.31 & 4.44 & $\begin{array}{l}\text { - Important to meet residents' expectations for farm } \\
\text { appearance, particularly in the off season }\end{array}$ \\
\hline
\end{tabular}




\section{References}

Baltimore Neighborhood Indicators Alliance. (n.d.). Community profiles. Retrieved July 24, 2014, from http://bniajfi.org/vital signs/cprofiles/

Baltimore Office of Sustainability. (n.d.). Homegrown Baltimore: Grow Local. Retrieved June 12, 2014, from http://www.baltimoresustainability.org/ homegrown-baltimore-grow-local

Besser, T. L. (1999). Community involvement and the perception of success among small business operators in small towns. Journal of Small Business Management, 37(4), 16-29.

Bracht, N., \& Tsouros, A. (1990). Principles and strategies of effective community participation. Health Promotion International, 5(3), 199-208. http://dx.doi.org/10.1093/heapro/5.3.199

Buchan, D. (2003). Buy-in and social capital: Byproducts of social impact assessment. Impact Assessment and Project Appraisal, 21(3), 168-172. http://dx.doi.org/10.3152/147154603781766266

Butterfoss, F. D. (2006). Process evaluation for community participation. Annual Review of Public Health, 27, 323-340. http://dx.doi.org/10.1146/ annurev.publhealth.27.021405.102207

Creswell, J. W. (2007). Qualitative inquiry and research design: Choosing among five approaches (2nd ed.). Thousand Oaks, California: Sage.

Gross, C. (2007). Community perspectives of wind energy in Australia: The application of a justice and community fairness framework to increase social acceptance. Energy Policy, 35(5), 2727-2736. http://dx.doi.org/10.1016/i.enpol.2006.12.013

Head, B. W. (2007). Community engagement: Participation on whose terms? Australian Journal of Political Science, 42(3), 441-454. http://dx.doi.org/10.1080/10361140701513570

Hoover, B. M. (2013). White spaces in black and Latino places: Urban agriculture and food sovereignty. Journal of Agriculture, Food Systems, and Community Development, 3(4), 109-115. http://dx.doi.org/10.5304/jafscd.2013.034.014

Hu, A., Acosta, A., McDaniel, A., \& Gittelsohn, J. (2011). Community perspectives on barriers and strategies for promoting locally grown produce from an urban agriculture farm. Health Promotion Practice, 14(1), 69-74. http://dx.doi.org/10.1177/1524839911405849
Kahn, E. B., Ramsey, L. T., Brownson, R. C., Heath, G. W., Howze, E. H., Powell, K. E., . . Corso, P. (2002). The effectiveness of interventions to increase physical activity: A systematic review. American Journal of Preventive Medicine, 22(4, Supp. 1), 73-107. http://dx.doi.org/10.1016/S0749_3797(02)00434-8

Kilkenny, M., Nalbarte, L., \& Besser, T. (1999). Reciprocated community support and small townsmall business success. Entrepreneurship and Regional Development, 11(3), 231-246. http://dx.doi.org/10.1080/089856299283182

Mann, S., \& Kögl, H. (2003). On the acceptance of animal production in rural communities. Land Use Policy, 20(3), 243-252. http://dx.doi.org/10.1016/S0264-8377(03)00025-5

Meenar, M. R., \& Hoover, B. M. (2012). Community food security via urban agriculture: Understanding people, place, economy, and accessibility from a food justice perspective. Journal of Agriculture, Food Systems, and Community Development, 3(1), 143-160. http://dx.doi.org/10.5304/jafscd.2012.031.013

Morgan, L. M. (2001). Community participation in health: Perpetual allure, persistent challenge. Health Policy and Planning, 16(3), 221-230. http://dx.doi.org/10.1093/heapol/16.3.221

Poulsen, M. N., \& Spiker, M. L. (2014). Integrating urban farms into the social landscape of cities: Recommendations for strengthening the relationship between urban farms and local communities. Baltimore, Maryland: Johns Hopkins Bloomberg School of Public Health. Retrieved from http://www.livablefutureblog.com/wpcontent/uploads/2014/08/CommunityBuyinUrbanFarms_July2014.pdf

Van der Stoep, G. A. (2000). Community tourism development. In W. C. Gartner \& D. W. Lime (Eds.), Trends in outdoor recreation, leisure and tourism (pp. 309-321). Wallingford, UK: CABI. http://dx.doi.org/10.1079/9780851994031.0309

Wüstenhagen, R., Wolsink, M., \& Bürer, M. J. (2007). Social acceptance of renewable energy innovation: An introduction to the concept. Energy Policy, 35(5), 2683-2691. http://dx.doi.org/10.1016/j.enpol.2006.12.001 